УДК 159.9.075

https://doi.org/10.23947/2658-7165-2021-4-3-20-35

\title{
Взаимосвязь типов информационного усвоения с показателями готовности к переменам у представителей поколения Z
}

\author{
Хачатур М. Асланян, Денис Ф. Даутов* \\ Донской государственный технический университет, г. Ростов-на-Дону, \\ Российская Федерация \\ "E-mail: dautov-80@mail.ru \\ *ORCID ID: https://orcid.org/0000-0001-8147-5603
}

\section{Аннотация}

В статье представлены результаты исследования взаимосвязи типов инорормационного усвоения и показателей готовности к переменам у преАставителей поколения Z. Во ВвеАении Аан Краткий обзор феноменов инорормационного усвоения и готовности к переменам, Аано описание психологических особенностей преАставителей Z. Новизна исслеАования заключается в рассмотрении современных поАХОАОВ К психологическим особенностям пок^онения Z в Связи со способами работы с инфрормацией и готовности к изменениям окружающей среды. В разделе Методы описаны основные методики эмпирического исслеАования: «Реестр стиля информационного усвоения» А. Р. Грегоса и «Аичностная готовность к переменам» Р. Хезер. Аано описание выборки: 44 представителя поколения Z, мужского и женского пола, в возрасте 18-20 ^ет. В разделе Результаты изучены связи межАу различными типами инорормационного усвоения и параметрами готовности к переменам у представителей поколения Z. Установлены связи межАу показателями в абстрактно-произвольном типе усвоения инорормации и готовности к переменам, выраженными шкалой «смелосты; межАу показате^ями абстрактно-произвольного типа усвоения инорормации и такими шкалами готовности к переменам как «оптимизм», «страстносты», «аАаптивносты; межАу показателями абстрактно-послеАовательного типа усвоения инорормации и такой шкалой готовности к переменам как «адаптивносты); межАу конкретно-произвольным типом усвоения инфрормации и таким показателем готовности к переменам как шкала «оптимизм»; межАу показателями конкретно-послеАовательного типа усвоения информации и таким показателем готовности к переменам как шкала "алаптивносты; межАу показателями конкретно-послеАовательного типа усвоения инорормации и показателями по шкале «уверенносты); межАу показателями конкретно-последовательного типа усвоения инорормации и готовностью к переменам по шкале «находчивосты» и «толерантносты». В ОбсужАении результатов провеАён 
Innovative Science: psychology. pedagogy. defectology 2021 VOL. 4 \# 3

GENERAL PSYCHOLOGY, PERSONALITY PSYCHOLOGY, HISTORY OF PSYCHOLOGY

анализ психологических особенностей представителей поколения в соответствии с найденными взаимосвязями.

\title{
КАючевые слова
}

поколение Z, цифровое поколение, тип информационного усвоения, психологическая готовность, готовность к переменам

\section{Для цитирования}

Асланян Х. М., Даутов Д. Ф. Взаимосвязь типов информационного усвоения с показателями готовно-сти к переменам у представителей поколения Z // Инновационная наука: психология, педагогика, дефектология. 2021. T. 4, № 3. C. 20-35. doi: https://doi.org/10.23947/2658-7165-2021-4-3-20-35

\section{The relationship of the types of information assimilation with indicators of readiness for change in representatives of Generation Z}

\author{
Khachatur M. Aslanyan, Denis F. Dautov* \\ Don State Technical University, Rostov-on-Don, Russian Federation \\ "E-mail: dautov-80@mail.ru \\ *ORCID ID: $\underline{\text { https://orcid.org/0000-0001-8147-5603 }}$
}

\begin{abstract}
The article presents the results of a study of the relationship between the types of information assimilation and indicators of readiness for change among representatives of Generation Z. In the Introduction, a brief overview of the phenomena of information assimilation and readiness for change is given, a description of the psychological characteristics of representatives of $Z$. The novelty of the research lies in the consideration of modern approaches to the psychological features of $Z$ worship in connection with the ways of working with information and readiness for environmental changes. The Methods section describes the main methods of empirical research: "The register of the style of information assimilation" by A. R. Gregos and "Personal readiness for change" by $\mathrm{R}$. Heather. The sample description is given: 44 representatives of generation $\mathrm{Z}$, male and female, aged 18-20 years. In the Results section, the relationships between different types of information assimilation and the parameters of readiness for change in representatives of Generation Z are studied. The relationships between the indicators in the abstract-arbitrary type of information assimilation and readiness for change, expressed by the "courage" scale, are established; between indicators of an abstractarbitrary type of information assimilation and such scales of readiness for change as
\end{abstract}


"optimism", "passion", "adaptivity"; between indicators of an abstract-sequential type of information assimilation and such a scale of readiness for change as "adaptivity"; between a concrete-arbitrary type of information assimilation and such an indicator of readiness for change as the "optimism" scale; between indicators of a concretesequential type of information assimilation and such an indicator of readiness for change as the "adaptivity"scale; between indicators of a specific-sequential type of information assimilation and indicators on the "confidence" scale; between indicators of a specific-sequential type of information assimilation and readiness for change on the "resourcefulness" and "tolerance"scale. In the Discussion of the results, the analysis of the psychological characteristics of the representatives of the generation was carried out in accordance with the relationships found.

\section{Keywords}

generation Z, digital generation, type of information assimilation, psychological readiness, readiness for change

\section{For citation}

Aslanyan, Kh. M., Dautov, D. F. (2021). The relationship of the types of information assimilation with indicators of readiness for change in representatives of Generation Z. Innovative Science: psychology, pedagogy, defectology, 4(3), 20-35. doi: https://doi. org/10.23947/2658-7165-2021-4-3-20-35

\section{Введение}

В настоящий момент времени, современных студентов можно назвать представителями первого поколения, с самого рождения погружённых в цифровую масс-медиа среду. Актуальная значимость исследования этого поколения обусловлена тем, именно тем, что такое состояние информационной среды сформировалось впервые в истории человечества и исследование цифрового поколения представляет большой научный и практический интерес, в связи с большой контрастностью информационной среды, в которой проходило их формирование. Цифровое поколение $\mathbf{Z}$ с самого раннего детства воспитывалось в богатой информацией среде. Данное поколение первое, которое было рождено в цифровом социуме (Носова, Кужелева-Саган, 2013).

Поколения, как тема психологических исследований, получила своё развитие в последней четверти двадцатого века. Этими вопросами занимадись ещё такие исследователи как В. Штраус и Н. Хоув (Сиврикова, 2015). Непосредственный интерес к этому направлению исследований появился на основе осознания факта, что каждое поколение имеет свои мировоззренческие черты, которые во многом отличаются или даже противоречат у представителей раздичных поколений. Среди отечественных и зарубежных психологов, занимавшихся изучением поколенческой 
проблематики, можно отметить таких авторов как: Н. В. Азаренок, Н. А. Зайцева, А. Б. Кулакова, В. Г. Ланкин, В. И. Пищик и целый ряд других (Азаренок, 2009; Зайцева, 2015; Кулакова, 2018; Ланкин, Григорьева, 2009; Sivrikova, 2015; Pishchik, \& Postnikova, 2020; Dautov, Korochentseva \& Al Hussini, 2019).

Раздичные теории подразумевают оригинальные границы хронологии, предлагаемые в качестве основной для определённого поколения. Большинство исследователей сходятся во мнении, что датой рождения поколения $\mathrm{Z}$ является 2000 год и далее по настоящее время. Это поколение ещё только формирует свои черты. В соответствии с теорией поколений может существовать некоторая цикличность, которая предполагает, определённое сходство поколения Z с так называемым «модчаливым поколением», родившимся с 1923-1943 годы (Кулакова, 2018). Предпосылками такого сходства является тот факт, что современное поколение неуклонно сокращает долю реального общения, замещая его дистанционным. В целом представители этого поколения более скдонны ценить виртуальное взаимодействие, чем взаимодействие лицом к лицу (Pishchik \& Spivachuk, 2020; Носова, Кужелева-Саган, 2013).

Для представителей цифрового поколения, в отличие от представителей иных поколений, специфика мышления и мыслей, приводят к фрагментации мыслительной деятельности, делая её поверхностной. В одной из своих работ А. Б. Кулакова, исследуя теоретические аспекты поколения $Z$, отмечала, что у этого поколения присутствуют такие свойства, как высокая скорость обучения и обработки информации, хорошая переключаемость с одного вида деятельности на другую, высокие показатели многозадачности. Всё это, по мнению исследователя, повышает эффективность действий в быстро меняющихся условиях среды. Уникальность поколения Z - в уверенном владении информацией, что должно повышать и уверенность в себе. Также к особенностям данного поколения относится высокий уровень клипового мышления (Кулакова, 2018). Этот тип мышления, которым зачастую является преобладающим у поколения Z, имеет определённые недостатки, но при этом облегчает многозадачность деятельности. Плата за такую многозадачность, довольно значительное нарушение раздичных когнитивных функций, в первую очередь функций внимания и логического мышления. Существенные проблемы со вниманием и склонность к визуальной символике вместо текстовой информации, во многом определяют характерологические особенности представителей поколения (Зайцева, 2015).

В связи с этими особенностями поколения Z, возникает вопрос об специфики информационного усвоения и готовности к переменам у его представителей, как определяющими для их взаимодействия с внешним миром.

Под информационным усвоением, как правило, понимается система связей в воспринимаемом через органы чувств знании, которое оценивается через сознание или когнитивную сферу личности. 
При понимании данного определения следует учитывать проблему раздичения таких понятий как «информация» и «знание», которые в научных источниках часто воспринимаются, как идентичные иди синонимичные.

По мнению Костроминой С. Н., такое взаимозаменяемое исподьзование понятий зачастую происходит в случаях, когда исследователи говорят о процессе обмена знаниями. Основной причиной этой замены может явАЯться субъектная природа знаний в обучении (Костромина, Гнедых, 2015).

На настоящий момент существует большое разнообразие подходов при описании механизма и основных закономерностей создания новых знаний в процессе обучения.

Ещё одна теория усвоения информации в обучении основана на концепции алгоритмизации, как способа эффективного усвоения информации. Процесс алгоритмизации предполагает чётко сформулированный набор предписаний, самостоятельно или с посторонней помощью, в которых детализировано представлен способ достижения результата определённой работы с информацией, предполагающей изучение конкретных вопросов, информационных блоков или навыков. Такие алгоритмы могут включать достаточно длинные последовательности действий и определённые приемы усвоения знаний (Мусс, 2014).

Такой исследователь как В. А. Крутецкий обращает внимание на два определяющих момента при работе с информацией - это тренировка наблюдательности в процессе обучения и наглядность представляемых материалов. Обязательным в таком случае становится необходимость создания связей между словесной и образной наглядностью (Крутецкий, 2006).

Всё вышесказанное, может означать, что сам по себе феномен информационного усвоения подразумевает своеобразный путь получения индивидом опыта из внешней среды. При усвоении всей поступающей извне информации, она проходит ряд этапов обработки, что и приводит в конечном итоге к овладению теми или иными знаниями. Усвоенная и переработанная человеком информация, в результате формирует в психике систему знаний. Этим знаниям придаются определённые смыслы и значения, являющиеся продуктами серии трансформаций индивидом полученной информации. В этом случае, нельзя отрицать, что процесс информационного усвоения и обучения знанию имеют набор общих черт. Понятия являются необходимыми для передачи, как информация, так и знания. Однако в случае с информацией, эти понятия могут сохраняться и передаваться в форме изображений или текста. Знание же, представлено набором индивидуальных понятийных структур человеческой психики, которые способны отражать события окружающего мира.

Переходя к рассмотрению феномена готовности к переменам, следует подчеркнуть, что это целостный феномен личности, который складывается из таких факторов, как психическая направленность, направленность на результат 
и эмоциональная устойчивость (Краснорядцева, 2012). Ряд авторов предпочитают рассматривать данное понятие как психическую готовность, которая возникает на том или ином этапе как своеобразный ресурс, способный обеспечить активность человека в изменчивой среде. Феномен психологической готовности, как правило, занимает доминирующее положение по отношению ко всем остальным видам готовности. Психологическая готовность, проявляется в виде системы, интеллектуадьных, волевых, мотивационных и эмоциональных компонентов человеческой психики, связанных с внешними условиями конкретной личности (Щербаков, Могилевская, 2016; Aboobaker \& Zakkariya, 2021).

Р. М. Шамионов рассматривает психологическую готовность как состояние готовности психики сопровождаться некоторым психическим напряжением. Это напряжение может позволить сохранять настрой на адаптацию к определённой ситуации с позиций реализации человеком потребности самой ситуации, и кроме того, ряда средств для приспособления к ней (Шамионов, 2017).

С позиций дичностного подхода рассматривается готовность П. А. Рудиком. По его мнению, в психической готовности наибодьшее значение имеют познавательные процессы, способные находить своё выражение в совершаемой деятельности, усиливая или ослабляя активность и волевые характеристики личности (Кучерявенко, Комисова, 2020).

К. К. Платонов в своей концепции личности, выделял моральную, профессиональную и психологическую готовность. При этом такое состояние в его подходе к пониманию дичности может быть отнесено к особым состояниям психики, которые способны обеспечить высокий уровень активности (Санжаева, 2016).

Ряд таких исследователей как В. А. Крутецкий, А.В.Качалко, Ю. А. Грачев отмечают интегральный характер, синтез дичностных свойств, определяющих пригодность этой дичности к совершаемой деятельности, решаемых человеком задачах (Грачев, 2011; Качалко, Кандыбович, 2009; Крутецкий, 2006; Костромина, Гнедых, 2015).

Готовности к переменам, является феноменом личности, прямо связанным с психической готовностью как таковой. М. И. Фаерман подходил к рассмотрению готовности к переменам, с позиций интегративного подхода. В соответствии с этим подходом, готовность рассматривается как один из этапов цикла, ряда изменений на уровне личности и группы (Брынза, 2015).

И. В. Брынза, рассматривая готовность к переменам как наличествующий ресурс психики, полагала, что социально - психологические проявления, которые способны выступать, в качестве средств реализации личностных целей, обеспечивают её через специфическую форму адаптации и саморегуляции. Данный ресурс в полной мере может раскрыться в соответствии с некоторой субъективной позиции человека. Кроме того, в своем исследовании И. В. Брынза 
смогла определить зависимость психического ресурса готовности к переменам от благополучия самой личности (Брынза, 2015).

А. В. Ааврик предполагал, что готовность к переменам во многом испытывает зависимость непосредственно от тех дичностных ресурсов и способностей в их дальнейшем развитии, которыми обладает человек. При этом, с точки исследователя, раздичные ресурсы, проявляясь при взаимодействии человека с окружающей средой как интегральный процесс деятельности, выполняют неодинаковую роль в приспособлении человека к жизненным ситуациям (Даврик, 2014).

Гершкович Т. Б., занимаясь исследованием возрастных изменений человека, отметил в одной из своих работ, что изменение выраженности готовности к переменам на протяжении всего жизненного пути, может быть охарактеризована через осознание процессов старения. Такой вывод можно сделать на основе усиление интенсивности субъективных переживаний по поводу возрастных изменений и, как следствие, значительному снижению способностей изыскивать способы, способствующие увеличению ресурсов к поиску жизненных перемен (Гершкович, Глуханюк, 2005).

Исходя из вышесказанного, можно закдючить, что готовность к переменам, в первую очередь является интегральным процессом, объединяющим множество психических проявлений человека, который активизирует его когнитивные и эмоционально-волевые ресурсы и, в конечном итоге, позволяют ему эффективно работать с теми воздействиями, которые поступают из внешней среды (Rafferty \& Minbashian, 2019).

\section{Методы}

Для определения стиля информационного усвоения была выбрана методика «Реестр стиля информационного усвоения» А. Р. Грегоса. Методика предназначена для диагностики раздичных моделей усвоения и восприятия информации из окружающего мира. Для диагностики дичностной готовности к переменам у представителей поколения Z был использован опросник «Дичностная готовность к переменам» PCRS P. Хезер. Эта методика позволяет оценить реакцию на ситуации, которые возникают в связи с какими-либо переменами.

Всего в исследовании приняли участие 44 представителя поколения Z, как мужчин, так и женщин, в возрасте 18-20 лет.

\section{Результаты}

Дия нахождения связей между полученными показателями информационного усвоения и готовностью к переменам у представителей поколения Z, также был применен коэффициент корреляции Пирсона. 
Innovative Science: psychology. pedagogy. defectology 2021 VOL. 4 \# 3

GENERAL PSYCHOLOGY, PERSONALITY PSYCHOLOGY, HISTORY OF PSYCHOLOGY

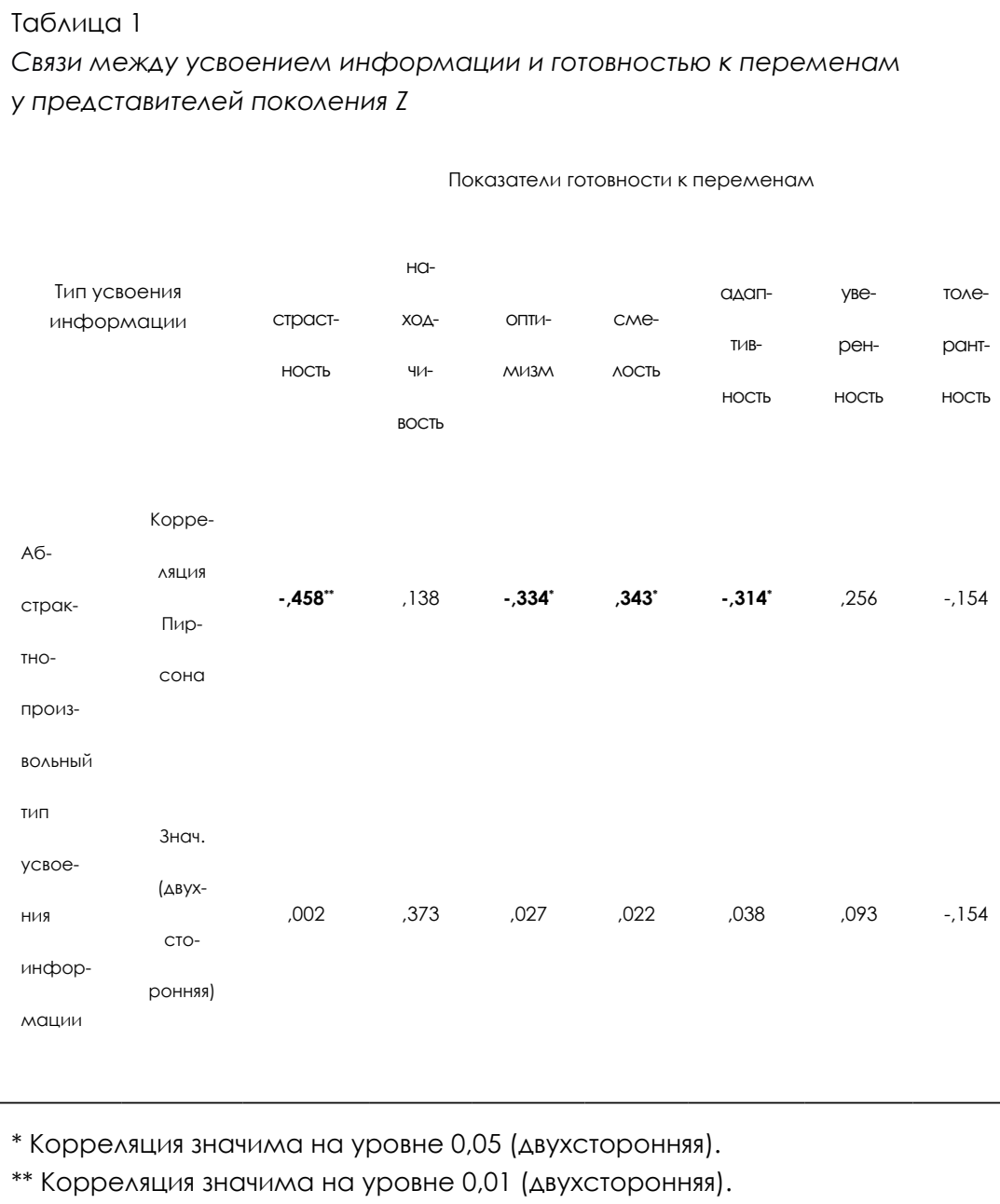

THO-

сона

произ-

вольный

тип

знач.

усвое-

ния

(AByx-

сто-

.002

.373

, 027

.022

инорор-

ронняя)

мации

* Корреляция значима на уровне 0,05 (Авухсторонняя).

** Корреляция значима на уровне 0,01 (Авухсторонняя).

Выявлена значимая положительная корреляционная связь между показателями в абстрактно-произвольном типе усвоения информации и готовности к переменам, выраженными шкалой «смелость» $\left(0,343^{*}\right)$.

Кроме того, у представителей данного поколения, выявлены следующие отрицательные корреляционные связи между показателями абстрактно-произвольного типа усвоения информации и такими шкалами готовности к переменам как «оптимизм» $\left(-0,334^{*}\right)$, «страстность» $\left(-0,458^{* *}\right)$ и «адаптивность» $\left(-0,314^{*}\right)$. 
Инновационная наука: психология. педагогика. дефектология 2021 TОМ 4 № 3

ОБШАЯ ПСИХОЯОГИЯ, ПСИХОЯОГИЯ ЯИЧНОСТИ, ИСТОРИЯ ПСИХОЯОГИИ

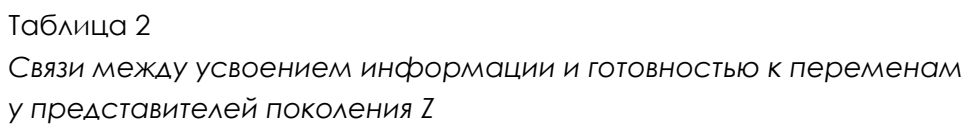

инорор-

мации

$$
\text { няя) }
$$

* Корреляция значима на уровне 0,05 (Авухсторонняя).

**Корреляция значима на уровне 0,01 (Авухсторонняя).

Из данных таблицы видно, что представители поколения Z, обнаруживают отрицательную корреляционную связь между показателями абстрактно-последовательного типа усвоения информации и готовностью к переменам, которая определяется шкалой «адаптивность» $\left(0,303^{*}\right)$. Соответственно, чем более высокие результаты в показателях абстрактно-последовательного типа усвоения информацией демонстрируют в представители поколения, тем менее выражена у них готовность к переменам в раздичных ситуациях. 
Innovative Science: psychology. pedagogy. defectology 2021 VOL. 4 \# 3

GENERAL PSYCHOLOGY, PERSONALITY PSYCHOLOGY, HISTORY OF PSYCHOLOGY

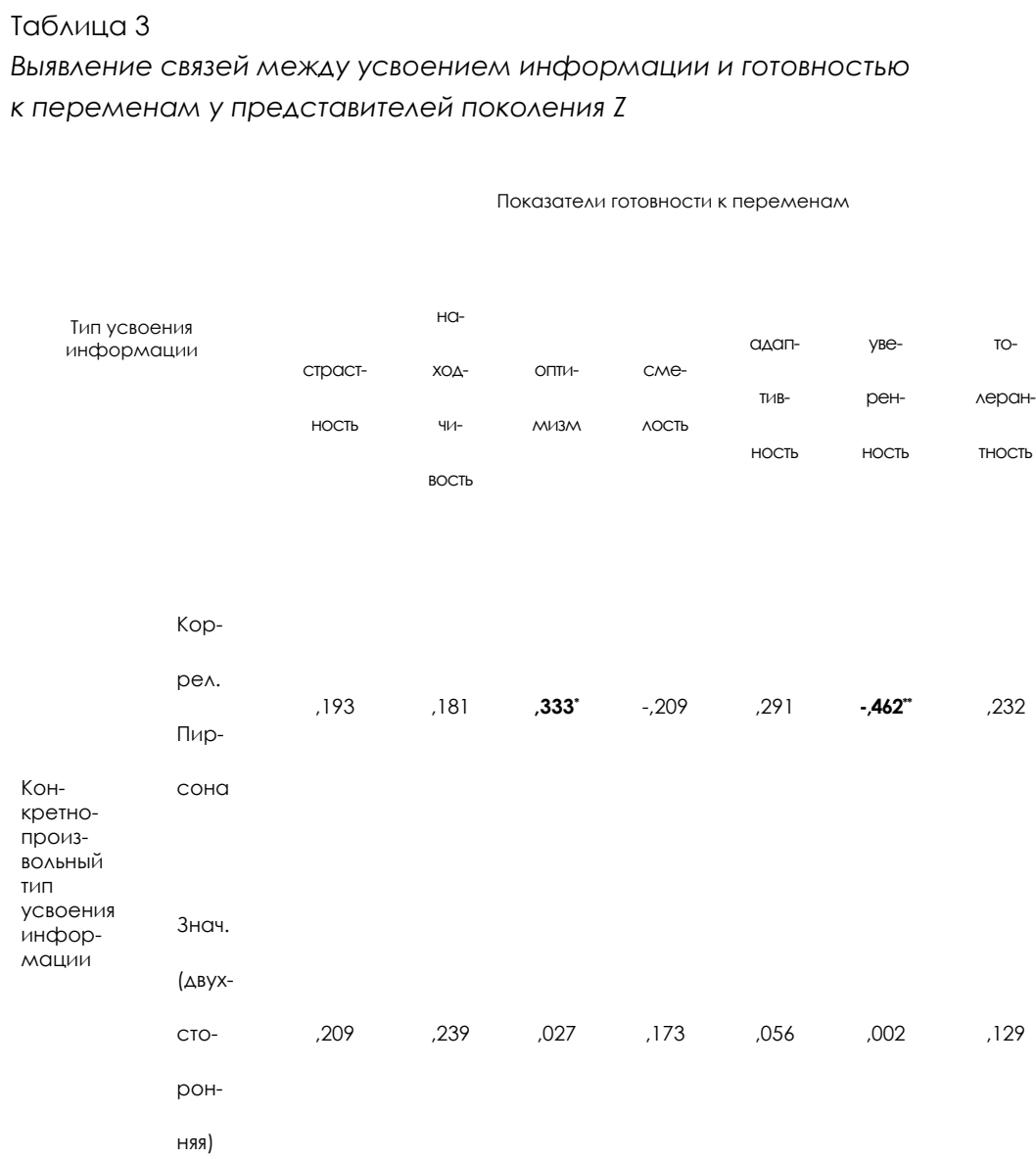

Пир-

сона

кретно-

произ-

вольный

Тип

усвоения

инорор- Знач.

мации

$(\Delta \mathrm{B} y \mathrm{x}-$

сто-

poH-

Няя)

* Корреляция значима на уровне 0,05 (Авухсторонняя).

**Корреляция значима на уровне 0,01 (Авухсторонняя).

Корреляционный анализ позволил выявить наличие значимой положительной связи между таким показателем готовности к переменам как шкала «оптимизм» $\left(0,333^{*}\right)$ и конкретно-произвольный типом усвоения информации.

Также была обнаружено наличие значимой отрицательной корреляционной связи между готовностью к переменам по шкале «уверенность» $\left(-0,462^{* *}\right)$ и конкретно-произвольным типом усвоения информации. 
Инновационная наука: психология. педагогика. дефектология 2021 TОМ 4 № 3

ОБЩАЯ ПСИХОЯОГИЯ, ПСИХОЯОГИЯ АИЧНОСТИ, ИСТОРИЯ ПСИХОЯОГИИ

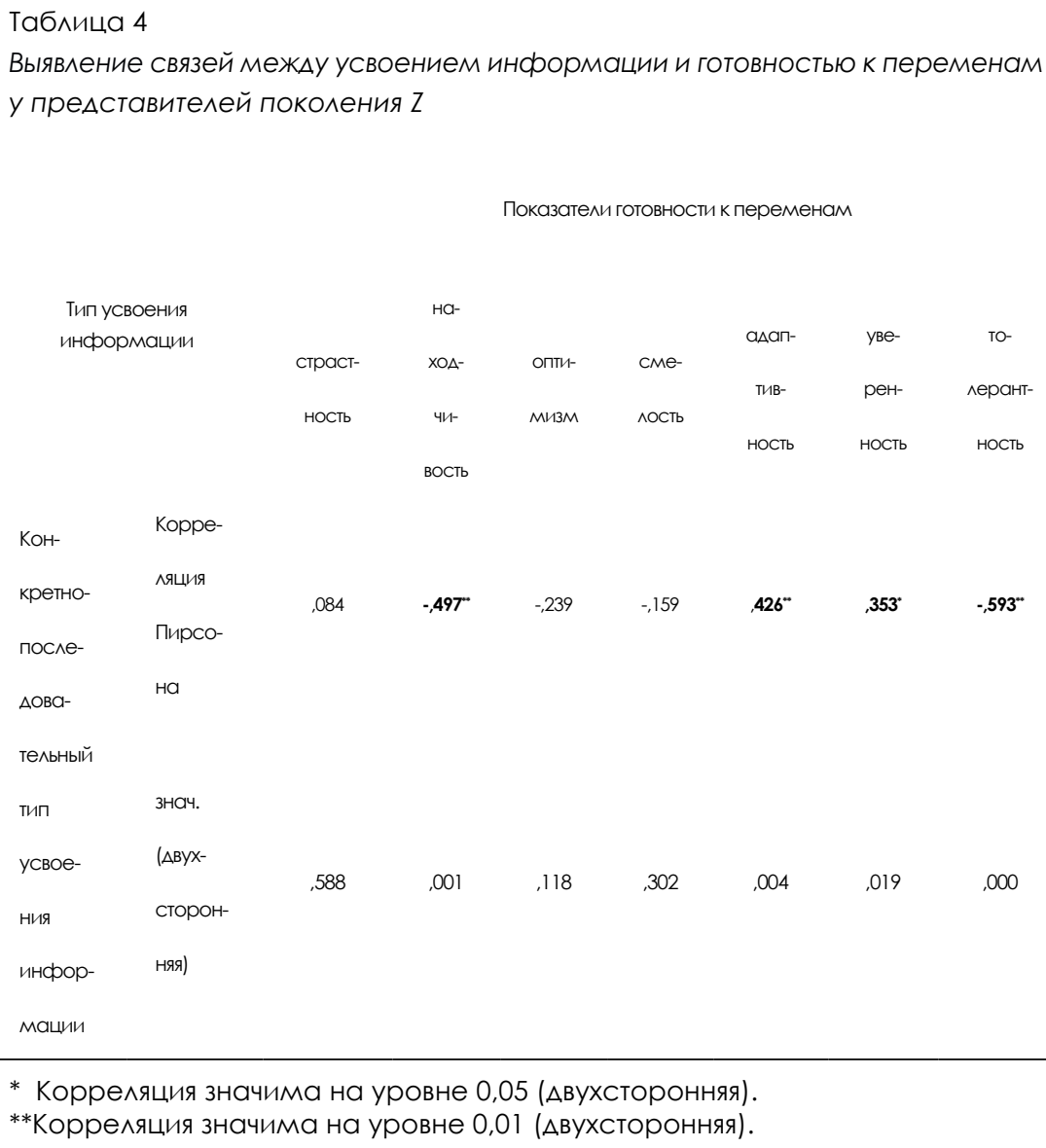

* Корреляция значима на уровне 0,05 (Авухсторонняя).

**Корреляция значима на уровне 0,01 (Авухсторонняя).

Из таблицы 4 видно, что существует значимая положительная связь между таким показателем готовности к переменам как шкала «адаптивность» $\left(0,426^{* *}\right)$ и показателями конкретно-последовательного типа усвоения информации у поколения Z. При этом наличие положительной корреляционной связи между показателями по шкале «уверенность» $\left(0,353^{*}\right)$ и показателями конкретно-последовательного типа усвоения информации.

Кроме того, обнаружена значимая отрицательная корреляционная связь между показателями конкретно-последовательного типа усвоения информации и готовностью к переменам по шкале «находчивость» $\left(-0,497^{* *}\right)$ и «толерантность» $\left(-0,593^{* *}\right)$. 
Innovative Science: psychology. pedagogy. defectology 2021 VOL. 4 \# 3

GENERAL PSYCHOLOGY, PERSONALITY PSYCHOLOGY, HISTORY OF PSYCHOLOGY

\section{Обсуждение резудьтатов}

Полученные результаты позволяют соотнести параметры готовности к перемене с определённым типом информационного усвоения у представителей поколений Z.

Чем выше склонность к абстрактно-произвольному мышлению, тем более выражена у них готовность к переменам. Это свидетельствует о том, что у представителей поколения $Z$, которые имеют высокие значения в абстрактно-произвольном типе усвоения информации, склонны воспринимать перемены в целом положительно, с готовностью к дальнейшим изменениям ситуации.

Чем больше выражен абстрактно-произвольный тип усвоения информации, тем слабее у представителей поколений Z проявляется оптимизм и энергичность. Это может свидетельствовать, о надичии у этих представителей, имеющих высокие показатели абстрактно-произвольного типа усвоения информации, незначительной склонности к переменам, отсутствие веры в собственную успешную деятельность. Кроме того, это может демонстрировать не желание видеть выход из трудных ситуаций, а также низкую адаптацию и не готовность к поиску новых путей при решении своих проблем.

Представители поколения $\mathrm{Z}$, имеющие абстрактно-произвольный тип усвоения информации, в меньшей степени готовы к жизненным переменам, чем обладатели других типов мышления.

Представители поколения Z, обладающие абстрактно - последовательным типом усвоения информации, имеют сложности в адаптации к сложным жизненным ситуациям.

Представители поколений Z, с преобладанием конкретно-последовательного типа усвоения информации, обладают сформированной готовностью к переменам, но при этом они имеют невысокие показатели толерантности к неопределенности. У них понижена способность к самообладанию в ситуациях, когда не ясна суть происходящего, они склонны терять контродь над ситуацией. Чем больше у представителей поколения Z выраженность этого типа усвоения информации, тем проще им даётся адаптация к изменяющимся ситуациям, и легче принимать решения в изменяющихся условиях, ведущих к переменам в их жизни. Выяснилось, что, чем выше выражен данный тип усвоения информации, тем меньше у представителей поколения $Z$ вера в свои собственные силы, и тем меньше они испытывают уверенность в возможности самостоятельно добиться значимого результата в своей деятельности. Кроме того, чем больше представители поколения демонстрируют развитие конкретно-последовательного типа усвоения информации, тем менее они способны реализовать такие качества как готовность к переменам, толерантность и находчивость.

Авторь заявляют об отсутствии конфликта интересов. 
Инновационная наука: психология. педагогика. дефектология 2021 TОМ 4 № 3

ОБШАЯ ПСИХОЯОГИЯ, ПСИХОЯОГИЯ ЯИЧНОСТИ, ИСТОРИЯ ПСИХОЯОГИИ

\section{Дитература}

Азаренок, Н. В. (2009). Клиповое сознание и его вдияние на психологию человека в современном мире. В А. А. Журавлев (ред.) Психология человека в современном мире. Том 5. Аичность и группа в условиях социальных изменений. Материалы Всероссийской юбилейной научной конференции, посвященной 120-летию со дня рождения С. А. Рубинштейна (С. 110-112). М.: Издательство «Институт психологии РАН».

Брынза, И. В. (2015). Готовность к изменениям как психологический ресурс личности в достижении благополучия. Science and Education a New Dimension. Pedagogy and Psychology, 3(31)(61), 69-73.

Гершкович, Т. Б., Глуханюк, Н. С. (2005). Готовность к освоению возрастновременных изменений в процессе жизненного пути. Образование и наука, 5, 90-99.

Грачев, Ю. А. (2011). Понятие «готовности к деятельности» в системе современного психолого-педагогического знания. Вестник Санкт-Петербургского университета МВД России, 52(4), 172-175.

Зайцева, Н. А. (2015). Теория поколений: мы разные иди одинаковые? Российские регионы: взгляд в будущее, 2(3), 220-236.

Качалко, А. В., Кандыбович, А. А. (2009). Научное обоснование модели формирования психологической готовности к профессиональной деятельности. Веснік Мазырскага дзяржаўнага педагагічнага ўніверсітэта імя I. П. Шамякіна, 2(23), 97-102.

Костромина, С. Н., Гнедых, Д. С. (2015). Информация и знание: подходы к пониманию процессов усвоения информации и формированию знаний в обучении. Вестник Аенинградского государственного университета им. А.С. Пушкина, 5(2). 5-14.

Краснорядцева, О.М.(2012). Психологическая готовность к инновационной деятельности учащихся и педагогов как характеристика образовательной среды. Вестник Томского государственного университета, 358, 152-157.

Крутецкий, В. А. (2006). Психологические особенности младшего школьника. В А. А. Семчук, А. И. Янчий (ред.) Хрестоматия по возрастной психологии. Гродно: ГрГУ.

Кулакова, А. Б. (2018). Поколение Z: теоретический аспект. Вопросы территориального развития, 2(42), 1-10. doi: https://doi.org/10.15838/tdi.2018.2.42.6

Кучерявенко, И. А., Комисова, О. С. (2020). Особенности психологической готовности студентов к профессиональной деятельности с разным отношением к ситуации неопределенности. Молодой ученый, 27(317), 150-152.

Даврик, А. В. (2014). Аичностные ресурсы как интегральная характеристика иичности. Гуманизация образования, 1, 44-47.

Аанкин, В. Г., Григорьева, О. А. (2009). Книга как информационно-технологическая основа культуры. Социологические исследования, 7, 78-84. 
Мусс, Г. Н. (2014). Алгоритмизация учебной деятельности как средство развития мыслительных операций младшего шкодьника. Аичность, семья и общество: вопросы педагогики и психологии, 40, 29-32.

Носова, С. С., Кужелева-Саган, И. П. (2013). Молодежь в сетевом информационно-коммуникативном обществе: зарубежные подходы к изучению проблемы. Сибирский психологический журнал, 49, 85-96.

Санжаева, Р. Д. (2016). Готовность и ее психологические механизмы. Вестник Бурятского государственного университета. Образование. Аичность. Общество, 2, 3-12.

Сиврикова, Н. В. (2015). Проблемы изучения поколений в психологии. Культурно-историческая психология, 11(2), 100-107. doi: https://doi.org/10.17759/ chp. 2015110210

Шамионов, Р. М. (2017). Отношение к изменениям и толерантность к неопределенности как предикторы адаптивности и адаптационной готовности. Российский психологический журнал, 14(2), 90-104. doi: https://doi.org/10.21702/ rpj.2017.2.5

Щербаков, Ю. И., Могилевская, В. Ю. (2016). Теоретический анализ феномена психологической готовности студентов к педагогической деятельности. Мир науки, культуры, образования, 5(60), 299-301.

Aboobaker, N., Zakkariya, K. A. (2021). Digital learning orientation and innovative behavior in the higher education sector: effects of organizational learning culture and readiness for change. International Journal of Educational Management. doi: https://doi.org/10.1108/IJEM-09-2019-0345

Dautov, D., Korochentseva, A., \& Al Hussini, M. K. M. (2019). Features of clip thinking and attention among representatives of generations $X$ and generations Z. In Trends in the Development of Psycho-Pedagogical Education in the Conditions of Transitional Society (ICTDPP-2019), SHS Web of Conferences 70, 06001. doi: https:// doi.org/10.1051/shsconf/20197006001

Pishchik, V., Postnikova, M. (2020). Digital generation representatives of various professional success levels: psychological features. In Innovative Technologies in Science and Education (ITSE-2020), E3S Web of Conferences 210, 22002. doi: https:// doi.org/10.1051/e3sconf/202021022002

Pishchik, V., Spivachuk, Z. (2020). The uniqueness of values and personal traits of Generation Z students in the innovative educational space of the southern region of Russia. In Innovative Technologies in Science and Education (ITSE-2020), E3S Web of Conferences 210, 18035. doi: $\underline{\mathrm{https}} / / /$ doi.org/10.1051/e3sconf/202021018035

Rafferty, A. E., Minbashian, A. (2019). Cognitive beliefs and positive emotions about change: Relationships with employee change readiness and changesupportive behaviors. Human Relations, 72(10), 1623-1650. DOI: https://doi. org/10.1177/0018726718809154 
ОБЩАЯ ПСИХОЯОГИЯ, ПСИХОЯОГИЯ ЯИЧНОСТИ, ИСТОРИЯ ПСИХОЯОГИИ

\section{References}

Aboobaker, N., \& Zakkariya, K. A. (2021). Digital learning orientation and innovative behavior in the higher education sector: effects of organizational learning culture and readiness for change. International Journal of Educational Management. doi: https://doi.org/10.1108/IJEM-09-2019-0345

Azarenok, N. V. (2009). Clip consciousness and its influence on human psychology in the modern world. In A. L. Zhuravlev (ed.) Human psychology in the modern world. Volume 5. Personality and group in conditions of social change. Proceeds of the All-Russian jubilee scientific conference dedicated to the 120th anniversary of the birth of S. L. Rubinstein (pp. 110-112). Moscow: Publishing house "Institute of Psychology RAS".(in Russ.).

Brynza, I. V. (2015). Readiness for change as a psychological resource of the individual in achieving well-being. Science and Education a New Dimension. Pedagogy and Psychology, 3(31)(61), 69-73. (in Russ.).

Dautov, D., Korochentseva, A., \& Al Hussini, M. K. M. (2019). Features of clip thinking and attention among representatives of generations $X$ and generations Z. In Trends in the Development of Psycho-Pedagogical Education in the Conditions of Transitional Society (ICTDPP-2019), SHS Web of Conferences 70, 06001. doi: https:// doi.org/10.1051/shsconf/20197006001

Gershkovich, T. B., \& Glukhanyuk, N. S. (2005). Readiness to master age-time changes in the process of life path. Education and Science, 5, 90-99. (in Russ.).

Grachev, Yu. A. (2011). The concept of "readiness for activity" in the system of modern psychological and pedagogical knowledge. Vestnik of the St. Petersburg University of the Ministry of Internal Affairs of Russia, 52(4), 172-175. (in Russ.).

Kachalko, A.V., \& Kandybovich, L. A. (2009). Scientific substantiation of the model of the formation of psychological readiness for professional activity. Vesnik of Mozyr State Pedagogical University named after I. P. Shemyakin, 2(23), 97-102. (in Russ.).

Kostromina, S. N., \& Gnedykh, D. S. (2015). Information and knowledge: approaches to understanding the processes of assimilation of information and the formation of knowledge in learning. Vestnik of the Leningrad State University named after A. S. Pushkin, 5(2). 5-14. (in Russ.).

Krasnoryadtseva, O. M. (2012). Psychological readiness for innovative activity of students and teachers as a characteristic of the educational environment. Vestnik of Tomsk State University, 358, 152-157. (in Russ.).

Krutetsky, V. A. (2006). Psychological features of the junior schoolboy. In L. A. Semchuk, A. I. Yanchiy (eds.) A textbook on age psychology. Grodno: Yanka Kupala State University of Grodno. (in Russ.).

Kucheryavenko, I. A., \& Komisova, O. S. (2020). Features of psychological readiness of students for professional activity with a different attitude to the situation of uncertainty. Young Scientist, 27(317), 150-152. (in Russ.). 
Kulakova, A. B. (2018). Generation Z: Theoretical Aspect. Territorial Development Issues, 2(42), 1-10. doi: https://doi.org/10.15838/tdi.2018.2.42.6 (in Russ.).

Lankin, V. G., \& Grigorieva, O. A. (2009). The book as an information and technological basis of culture. Sociological Research, 7, 78-84. (in Russ.).

Lavrik, A.V. (2014). Personal resources as an integral characteristic of personality. Humanization of Education, 1, 44-47. (in Russ.).

Mousse, G. N. (2014). Algorithmization of educational activity as a means of developing mental operations of a younger student. Personality, Family and Society: Questions of Pedagogy and Psychology, 40, 29-32. (in Russ.).

Nosova, S. S., \& Kuzheleva-Sagan, I. P. (2013). Youth in a network information and communication society: foreign approaches to the study of the problem. Siberian Psychological Journal, 49, 85-96. (in Russ.).

Pishchik, V., \& Postnikova, M. (2020). Digital generation representatives of various professional success levels: psychological features. In Innovative Technologies in Science and Education (ITSE-2020), E3S Web of Conferences 210, 22002. doi: https:// doi.org/10.1051/e3sconf/202021022002

Pishchik, V., \& Spivachuk, Z. (2020). The uniqueness of values and personal traits of Generation $Z$ students in the innovative educational space of the southern region of Russia. In Innovative Technologies in Science and Education (ITSE-2020), E3S Web of Conferences 210, 18035. doi: https://doi.org/10.1051/e3sconf/202021018035

Rafferty, A. E., \& Minbashian, A. (2019). Cognitive beliefs and positive emotions about change: Relationships with employee change readiness and change-supportive behaviors. Human Relations, 72(10), 1623-1650. DOI: https://doi. org/10.1177/0018726718809154

Sanzhaeva, R. D. (2016). Readiness and its psychological mechanisms. Vestnik of the Buryat State University. Education. Personality. Society, 2, 3-12. (in Russ.).

Sivrikova, N. V. (2015). Problems of generational research in psychology. Cultural and Historical Psychology, 11(2), 100-107. doi: https://doi.org/10.17759/ chp.2015110210 (in Russ.).

Shcherbakov, Yu. I., \& Mogilevskaya, V. Yu. (2016). Theoretical analysis of the phenomenon of psychological readiness of students for pedagogical activity. The world of Science, culture, education, 5(60), 299-301. (in Russ.).

Shamionov, R. M. (2017). Attitude to changes and tolerance to uncertainty as predictors of adaptability and adaptive readiness. Russian Psychological Journal, 14(2), 90-104. doi: https://doi.org/10.21702/rpj.2017.2.5 (in Russ.).

Zaitseva, N. A. (2015). Generational theory: are we different or the same?. Russian regions: a look into the future, 2(3), 220-236. (in Russ.). 